INTERNATIONAL DESIGN CONFERENCE - DESIGN 2018

https://doi.org/10.21278/idc.2018.0534

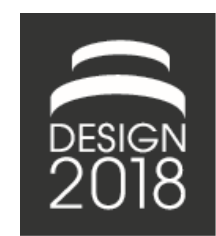

\title{
PRODUCT DEVELOPMENT CHALLENGES FOR SPACE SUB-SYSTEM MANUFACTURERS
}

\author{
A. B. Öhrwall Rönnbäck and O. Isaksson
}

\begin{abstract}
Space industry undergoes a transformation where new business interests affect manufacturers of space subsystems and equipment. This paper investigates consequences on development and design capabilities following the increased competition and market volumes, towards emphasis on commercial values, seeking adaptable, flexible and production efficient design solutions.
\end{abstract}

Keywords: space industry, product development, technology development, innovation management

\section{Introduction}

Designing products and equipment for space has been a challenge for designers, combining minimal weight with high reliability and for use in an environment where radiation, dynamics during launch, thermal conditions have promoted innovative solutions. Reliability is decisive, where design margins are narrow for launchers, and the limited ability to maintain and repair satellites during their long service. Both satellites and launching equipment were designed and used at a low production volume, and payload were typically one-off designs such as scientific instruments. As estimates for increased payloads started to increase, pre-requisites for design and manufacturing raised to another category of challenges. In 2010, according to Worldwide Mission Model by Teal Group, there were 2,229 space payloads proposed for launch to earth or lunar orbits or deep space trajectories. Between 2010-2029 that estimate increased to 12,500 payloads. For example, adaptability, flexibility and produceability requirements of technologies and sub-system designs increase (Ekpo, 2012). At the same time, the miniaturization enable smaller and clustered satellites to provide an increasingly capable set of functionalities. Also launcher technologies become subject to increased cost effective expectations, and re-useable solutions emerge.

As a business, the space service sector undergoes a transformation, where new business interests and plans affect current manufacturers and attracts new actors. No longer are space applications a market where mainly large governmental institutions set the gameplan. Instead several new commercial actors enter, hand-in-hand with governmental bodies (NASA, 2014a). From a design point of view, there are order of magnitude expectations on cost and lead time reduction, increased production efficiency and in general a stronger emphasis on commercial customer values. Among the drivers for change that lead to increased variety, functionality and volume of produced space products and equipment, are for example the need to better understand earth conditions with data from space, such as weather forecasts, climate change, or more accurate observations of criminal activities, and the plans to provide global connectedness and internet for all, from the One Web initiative, using Low Earth Orbit (LEO) satellites (One Web, 2017). In this paper, the conditions for design of space products and applications are explored, discussing what consequences and opportunities that arise affecting design practices, methods, tools and strategies. What 
learnings can be seen for design organisations at manufacturers of sub-systems and equipment, for space applications, as the volume of production increase with an order of magnitude?

\subsection{Space industry in transition}

The building of products service systems (PSS) and various equipment for space applications are booming, both for scientific purposes and for existing and novel space industry applications, with increasing production volumes. (e.g. Lim, 2017)

The concept of small satellites and constellations of satellites has been focussed for years (Sandau et al., 2008). Such applications improve performance of both precision and functionality, at the same time as size, cost and complexity of each satellite can be reduced (Bacon and Oliviers, 2017). Scientific applications benefit from higher resolution and precision (e.g. Ijssel et al., 2015) and many applications are already underway, such as NASA's COSMIC with a system of six satellites, see Figure 1. Also for commercial applications, constellations are exploited (e.g. Space X, 2017), and the commercial interest in space applications is intriguing, where e.g. NY Times recently reported that SpaceX alone was valued to \$21BUSD (Benner and Chang, 2017).

Multiple coordinated satellites also drive the development of new satellite navigation technologies (Jin, 2017), as one example of how new applications drive technological development, and put simply; the business expectations and investments are significant and the competition on the market for manufacturers increases dramatically.

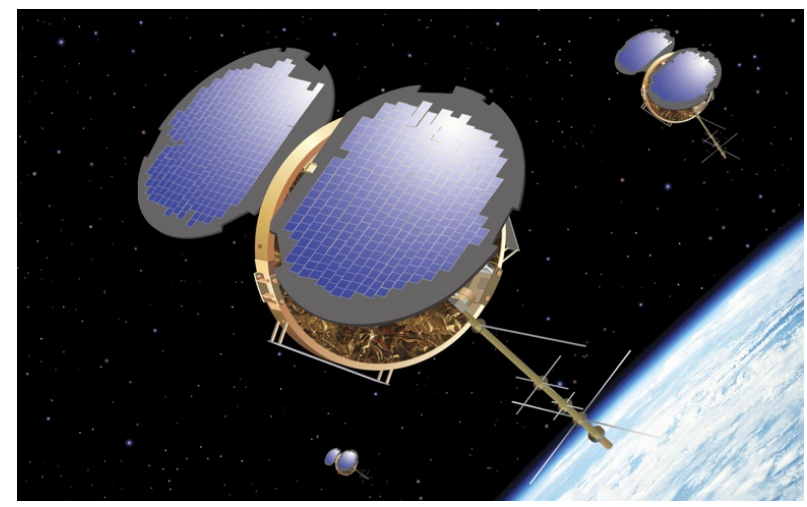

Figure 1. NASA's Constellation Observing System for Meteorology Ionosphere \& Climate (source: NASA, 2014b)

The impact on design practice and manufacturing is already visible, where low cost, off-the-shelf materials and design solutions are being re-considered for new products (Shao et al., 2017). At a recent conference, several cost competitive concepts were presented for both launchers and satellites (Hatton, 2017). The volume of production will increase significantly, and to meet the need for the 1000's of LEO satellites needed, new assembly plants are being set up (Airbus, 2017).

It is apparent that the booming business interest in space applications bring new actors, higher volumes of production and a step change in competitive markets, with a need to combine deep knowledge in space conditions with entrepreneurial and production efficiency focus. The reliability on satisfying availability of offered functionality to customers remains very high.

Table 1. Trends and their consequences for product development for manufacturers of space sub systems and equipment

\begin{tabular}{|l|l|}
\hline Observation & Consequences \\
\hline Market expansion & Increased time pressure, cost pressure and re-use of technologies \\
\hline More satellites in orbit & Tighter control in navigation and communication bandwidth \\
\hline Clustered satellites & Higher manufacturing volumes \\
\hline Miniaturization & New designs and manufacturing technologies \\
\hline Service providers & New and changed roles for partners, opening for PSS \\
\hline
\end{tabular}




\subsection{Problem formulation}

The growth in space business, and simultaneous transition of both business models, technologies and production conditions challenges the entire space domain. Established organisations, relying on experience gained over many decades, are faced with radical changes, and new actors on the market. It is relevant to articulate the challenges arising, and also what can techniques that can be adopted and brought into a new practice. Here, we delimit the study to manufacturers of mechanically dominated sub-systems and equipment and pose two guiding research questions.

RQ1: How does current trends in space industry affect design and development capabilities for space manufacturers?

RQ2: What design strategies can space manufacturers adopt from automotive and aeronautics businesses and vice versa?

\section{Research context and method}

This paper report from an ongoing research initiative where three Swedish manufacturers seek to meet the needs of next generation launcher and satellite equipment using novel and innovative design and manufacturing strategies. University researchers engage together with engineering teams within the three manufacturers in a participatory action research mode. Companies are responsible for defining use cases with representative data sets, sufficiently detailed to capture the product and product development context. Universities participate through facilitating dedicated collaborative workshops, where practitioners present and share progress made between workshops. University researchers further introduce design methods and capabilities that are used to clarify and organise the use case material. In addition to collaborative workshops, interviews with internal stakeholders at the companies are conducted to capture and understand the overall challenges in the business. Between 2015 and 2017, 8 interviews, one of them with a customer representative, were conducted.

Observations from workshops are recorded and analysed from both a technical and development process view, and compared with literature findings. In particular, observations have been made to identify what aspects stem from the increased competitiveness and expected volume increase on the market.

The observations and findings are compiled to allow product development researchers and practitioners to reflect on how design capabilities can (and most likely need to) change in space application design as a consequence of the business transition. The observations made also to enable a general discussion on how design practices can benefit from adopting experiences and learnings from other business domains, and what can be learnt from astronautical design experiences.

\section{Business domains and their influence on design}

For the purpose of this paper, the notation drivers for design capabilities will be used, where "drivers" are defined as the conditions that industries need to meet with changed capabilities. Design capabilities are the means to perform design tasks, and can be both methods and tools, technologies and human and organisational factors. The challenge is to articulate the most significant drivers for new, and improved design capabilities.

\subsection{Characteristics of design and manufacturing of space equipment and subsystems}

The space business is in the middle of a transition. For 60 years of capital intensive and state funded broad programs, delivering significant advancements for science and society, the market is opening for new actors. Since first successful private spaceflight initiative in 1982, and the SpaceShipOne with the first privately built manned spaceflight 2004, entrepreneurial forces have accelerated the impact on the core business of space industry. Today, there are fast growing businesses that rely on satellite enabled services for communication, surveillance, observation and scientific discovery and experimentation.

Space industry manufacturers have had a strong focus on performance and reliability of their products, with governmental programs as unique buyers in what could be labelled a monopsonic market (or oligopsonic), ie with one (or a few) buyers and several sellers (as a contrast to monopoly with one seller and several buyers). Not until lately, business competitiveness similar to the case in other industries, have become a true driver. The strong focus on science and problem solving has resulted in a strategic, 
durable and innovative culture, where problems are positively seen, and their solutions as results that can be useful across application areas, not only for space industry. The Technology Readiness Level, TRL, was developed at NASA to enable a simple way of focussing system reliability of advanced technological systems.

The practises/routines and methods rely in years of experience of highly specialized design of advanced "one off" products, which are necessary since both the launcher and satellite application domains set reliability a top priority. The emergence of more entrepreneurial actors has resulted in higher competition, new business models and from a design point of view - the acceptance of design solutions and materials that previously have been discarded.

In general, the space domain is mostly known for the contributions to innovative technologies that have spun-off also to other domains. There are many examples through history where space business has had a decisive influence on technology development, later to be deployed also on other applications. Well known are e.g. LASER technologies and Liquid Chrystal technologies (ref and example). One of the participating companies in this study have developed skills in advanced robot welding and patented designs for hydrogen cooled rocket nozzle walls, where the combined skills in design and manufacturing have paved the way for larger scale commercial applications in aerospace.

Based on the empirical observations, the following drivers for design capabilities for space equipment manufacturers are articulated:

1. Lead time and cost: Expected order of magnitude reduction of both time and cost for development to remain competitive increased the necessity to reuse design solutions and adopt design for new technologies that allow adaptively. There is also a drive towards less expensive and off-the-shelf solutions.

2. Commercial business development: OEMs are increasingly positioning themselves as service providers, as a response to delivering customer value, which challenge both technical and business interfaces and relations, i.e. requirements need to be negotiated and iterated more dynamically along the design process.

3. Reliability: While reliability expectations remain the same on system functionality, the miniaturization and clustered satellites offer new ways of relaxing expensive solutions on individual equipment.

\subsection{Comparing with design capabilities in automotive and aeronautics}

Design capabilities alter as technology development evolves along with business maturation cycles. Looking into another business domain, the automotive business is well into competitive phases of exploiting and refining products and services. Here, design methods for competitiveness have been dominated by efficiency, robustness and lead time reducing techniques. Over the last decades the need to differentiate on the market by value and technology offers have increased, and innovative products and companies are entering the market.

Aerospace, and especially aeronautics, have followed a similar pattern, yet delayed a few years in comparison and with different life-cycle time (cf e.g. Fine, 1995; Vaughn et al., 2002).

Questions can be raised if the expected increase in production volume for space equipment is likely to drive manufacturers to adopt a similar development evolution path.

In summary both automotive and aerospace businesses have had a strong influence on the development of design aids, and we have selected a few examples. The automotive business has led the introduction of design methods for assembly and automation in production as well for resource efficient design. Business competitiveness has been significant and global over decades already, and generically applicable methods and procedures such as Lean Production and Lean Product development, that address entire organisations collectively, have improved the ability to develop and produce products have been largely driven by automotive (Wheelwright and Clark, 1992).

Advances in the aerospace industry (including both aeronautics and astronautics) have been leading development of analytical and simulation driven digital design tools, with deep influence on how to master the physics of flight and match these with product design features. Aeronautics and Astronautics have developed a simulation driven culture where CAE tools have been adopted also to analyse and design product parameters that influence manufacturability. 
The ability to prepare for manufacturing and assembly is largely decided on during design. Design for Manufacturing and Assembly (DFMA) emerged as a means to meet the need to design products to fit efficiently into manufacturing and assembly (Boothroyd, 1994). Lean also influenced aerospace especially in the mid-late 1990s (LAI, see e.g. Vaughn et al., 2002). The way lean has been implemented amongst space manufacturers is less evident to date, other than the fact that several manufacturers in aerospace also share resources and organisation with space business units within the same corporations. Product Platform Design and Development has been developed as a design strategy to offer greater customer variety, without compromising development and production costs (Pirmoradi et al., 2014). Platform strategies have also been used as a means to build and use experiences into product families. Platform based design and development both need, and benefit, from systematic ways of organising product and production information and design methods and tools are being developed to take advantage of this structure as a means to achieve process efficiency (Landahl et al., 2016).

Computational tools have always been important in physics and mechanics of flight, and have motivated the development of, CAE (Computer Aided Engineering), where the space initiatives during 1960s was a clear driver for development of computer aided tools for design. Aircraft and Aeroengine design used computer aided tools based on Finite Element Analysis. During the 1980s and 1990s several initiatives for standardising exchange of product models such as STEP was led by aerospace organisations, especially in analytical and simulation domains. Boeing's development of the B777 aircraft became known to be the first aircraft to be $100 \%$ designed and pre-assembled in a computer. (Sharma and Bowonder, 2004)

\section{Observations and analysis of design challenges}

The domain specific drivers for developing design capabilities are used as a basis for a discussion of what potential benefits exist when developing design capabilities for manufacturing companies in space business. As a business domain matures, the tension increases in combining cost and lead time efficiency with an emerging need to make disruptive innovative shifts in product and technology. The need for competitive design methods are influenced both by the type of product context and the phase of business maturity.

Manufacturers of space equipment and applications are currently driven by a disruptive business situation at the same time as technologies are being developed and introduced at a higher rate.

Below follow observations and reflections on how the design capabilities may be affected, and presented here as a means to facilitate a discussion on the need of new design capabilities, both what can be learnt from astronautics and what astronautics can learn from other domains.

\subsection{Trends in industry affecting design and development capabilities}

The comparison with automotive and aeronautics indicate that important driving conditions for design capabilities differ somewhat between the business domains. All three are affected by disruptive technology development for both product functionality and production. Specifically, the automotive industry is dominated by their large-scale volume production and consumer orientation. Aeronautics is characterized by their long product life-cycles and development of service during operation in long-term business-to-business relations, and a strong focus on reduced environmental impact (Alonso-Rasgado et al., 2004). Still strongly focusing on reliability, development capabilities for astronautics are affected by expectations on market volume growth in combination with new technologies and new architectures, and re-use of components. Table 2 displays a selection of significant drivers for advancing design capabilities in the three business domains.

Table 2. Important drivers impacting design capabilities

\begin{tabular}{|l|l|l|}
\hline Automotive & Aeronautics & Astronautics \\
\hline $\begin{array}{l}\text { 1. Design for assembly (large } \\
\text { volumes) }\end{array}$ & 1. Simulation driven design & 1. Lead time and cost \\
\hline $\begin{array}{l}\text { 2. Design for integration of digital } \\
\text { technologies and new materials }\end{array}$ & 2. Life Cycle design & $\begin{array}{l}\text { 2. Commercial business } \\
\text { development }\end{array}$ \\
\hline 3. Design for process efficiency & 3. Servitization & 3. Reliability \\
\hline 4. Design for user experience & 4. Reduced CO2 emissions & \\
\hline
\end{tabular}


There are additional drivers, specifically addressing functional requirements fulfilment, such as thrust, fuel efficiency and more, that deliberately are omitted in the comparison.

\subsection{Learnings between businesses domains}

Manufacturers in automotive and aeronautics applications are currently competing and differencing by how well they integrated novel technologies into a system where success on market is a combination of traditional performance metrics and the satisfaction of user perceptions. A challenge for these businesses is to ensure reliability and functionality of the system, as the system depends on a large variety of contributing technologies from different domains. This has led to the development of flexible, adaptable products and product platforms. As space manufacturers are faced with higher volumes these capabilities are likely to be of increasing importance.

The very nature of space manufacturing has been, and still is, to develop technologies capable of solving problems which has not yet been solved. Techniques such as TRL to judge and compare alternative technologies readiness for a system have therefore already gained popularity in aerospace and automotive.

Design methods such as TRIZ (Altshuller, 1984) are used to find new ways of solving problems. Space manufacturers spend a significant time in experimentation and technology development phases and have developed systematic procedures to ensure validity of technologies that can go into products.

It is likely that manufacturing industries in automotive and aeronautics can benefit from the systematic, technology intensive, problem solving design approaches that characterises the astronautics manufacturing business. Experience of strong attention to system reliability while integrating technologies is increasingly important as technologies such as autonomous vehicles and artificial intelligence are introduced into already complex systems.

\section{Conclusions and discussion}

The paper has revisited design conditions in the space application domain, and made observations of how an ongoing transition in the space business opens for new needs to advance design practice in the space industry. At the same time, the context of developing applications for space has gained a broader interest outside the traditional space community.

One challenge for the astronautics and space manufactures is to successfully combine lead time and cost competitive product design process in an environment where conditions are extreme and design margins are narrow. Well established earth conditions and technologies, such as GPS for navigation, convective heat transfer etc. have required specific techniques to be developed. The challenge is now to combine this with a step change in cost and lead time efficiency, and adopt design methods to higher production volumes and even maintenance and re-use concepts.

Another challenge is that popular orbital paths are becoming crowded, where debris is substantial and can be detrimental upon collation. Also, frequencies for communication are becoming scarce. There is need for innovation, which will lead to new technologies, and even products and services, that have to be designed into the space domain.

A third challenge is the necessity to retain a strong focus on reliability, something that has until recently been a reason behind high costs. Both materials used and methods for verification have been expensive. Reducing cost while maintaining, or even improving, performance and reliability is a challenge.

A fourth challenge is the broader set of stakeholders that will bring expectations on space products. For human flights, passengers are not only scientists, but private passengers, that have a different set of expectations and needs.

Regarding the learnings to, and from, other domains than astronautics and space industry, it is too early to make clear conclusions, yet, as expected, there seems to be a true potential for manufactures of space applications to learn from other domains, such as automotive and aerospace (aeronautics). However, these capabilities need to be tailor-made and adapted to the conditions prevailing in space operations. Equally, the problem solving and scientific nature of astronautics where designers typically spend most of their time in technology development "mode", the space domain is a highly interesting business as a source of inspiration for creative problem solving and utilization of advanced and innovative design 
solutions. This paper has presented a first compilation of observations of design aspects in space application manufacturing.

In what way can then learnings be shared between the automotive, aeronautics, and astronautic domains? The expected increase in production volume and competition through speed to market and low cost focus, opens opportunities to reduce costs on a larger produced series of products. The competitive situation on the market, forces companies to adopt lead time and cost efficient design technologies. This situation has been the driving force in automotive, and increasingly also in aerospace, for a longer time. Platform based design strategies are being developed in the space manufacturing domain, both as a means to reduce cost and lead time, but perhaps even more importantly as a means of retaining risk control (Vaughn et al., 2002).

Customers requesting services from astronautics products have a more commercial view of the services enabled by space products and applications. It is expected that the breadth and variety of customer expectations increase, and there is a need to capture and manage these expectations and allow them to influence the design. Both automotive and lately also aerospace manufacturers have developed design capabilities to handle expectations and needs of stakeholders efficiently. Such methods include customer focus groups, modelling and simulation of perceived quality, configurational design techniques and value-driven development, and can be expected to grow in importance.

Low cost focus reinforced the need to develop re-useable concepts for launchers (SpaceX, 2017) and repair and maintenance strategies for satellites, and the design capabilities for life cycle design expands the "design space" of new products.

Regarding engineering tools, for e.g. modelling and simulation, the tools and techniques available in the market have predominately been developed to serve other business domains. As an example, the material models used in Finite Element Analysis (FEA) or CFD need to be able to account for non-earth conditions (since the ideal gas-law idealizations and linearized material behaviour do not apply). Often, manufacturers have to invest significant experimental work to ensure validity of models and simulation tools. As both automotive and aerospace are progressing and introducing more advanced simulation models, it is likely that astronautical manufactures will have more benefit from sharing also modelling and simulation technologies and methods.

\section{Acknowledgments}

The authors acknowledge financial support from the Swedish National Space Agency and the European Union, and the participating space industries.

\section{References}

Airbus (2017), OneWeb Satellites inaugurates serial production line for the Assembly, Integration, and Test of OneWeb's first satellites. [online] Airbus. Available at: http://www.airbus.com/newsroom/pressreleases/en/2017/06/one-web-satellites-serial-production-line-inauguration.html (accessed 29.12.2017).

Alonso-Rasgado, T., Thompson, G. and Elfström, B.-O. (2004), "The design of functional (total care) products", Journal of Engineering Design, Vol. 15 No. 6, pp. 515-540. https://doi.org/10.1080/09544820412331271176

Altshuller, G. (1984), Creativity as an Exact Science, Gordon \& Breach, New York, NY.

Bacon, A. and Oliviers, B. (2017), "Skimsats: bringing down the cost of Earth Observation", Proceedings of the 12th Reinventing Space Conference. https://doi.org/10.1007/978-3-319-34024-1

Benner, K. and Chang, K. (2017), SpaceX Is Now One of the World's Most Valuable Privately Held Companies. [online] NY Times. Available at: https://www.nytimes.com/2017/07/27/technology/spacex-is-now-one-ofthe-worlds-most-valuable-privately-held-companies.html?_r=0

Boothroyd, G. (1994), Product design for manufacture and assembly, Dekker, New York, NY.

Ekpo, S.C. and George, D. (2012), "A system engineering consideration for future-generations small satellites design”, 2012 IEEE First AESS European Conference on Satellite Telecommunications (ESTEL). https://doi.org/10.1109/ESTEL.2012.6400067

Hatton, S. (2017), Proceedings of the 12th Reinventing Space Conference, Springer, Cham. https://doi.org/10.1007/978-3-319-34024-1

Ijssel, J., Encarnação, J., Doornbos, E. and Visser, P. (2015), "Precise science orbits for the Swarm satellite constellation", Advances in Space Research, Vol. 56 No. 6, pp. 1042-1055. https://doi.org/10.1016/j.asr.2015.06.002 
Jin, S. (2017), "Preface: BeiDou Navigation Satellite System (BDS)/GNSS+: New developments and emerging applications", Advances in Space Research, Vol. 60 No. 12, pp. 2519-2918. https://doi.org/10.1016/j.asr.2017.11.021

Landahl, J., Levandowski, C., Johannesson, H., Söderberg, R., Wärmefjord, K. et al. (2016), “Using Product and Manufacturing System Platforms to Generate Producible Product Variants”, Procedia CIRP, Vol. 44, pp. 6166. https://doi.org/10.1016/j.procir.2016.02.132

Lim, D. (2017), "Thinking Differently about Standard Smallsat Interfaces- Let Adapters Take the Brunt", In: Hatton, S. (Ed), Proceedings of the 12th Reinventing Space Conference. https://doi.org/10.1007/978-3-31934024-1

NASA (2014a), Strategic Plan 2014, National Aeronautics and Space Administration.

NASA (2014b), Constellation Observing System for Meteorology Ionosphere \& Climate (COSMIC). [online] Available at: https://www.nasa.gov/directorates/heo/scan/services/missions/earth/COSMIC.html

One Web (2017), One Web Satellites. [online] Available at: http://www.oneweb.world/\#home (accessed 29.12.2017)

Pirmoradi, Z., Wang, G.G. and Simpson, T.W. (2014), “A Review of Recent Literature in Product Family Design and Platform-Based Product Development”, In: Simpson, T., Jiao, J., Siddique, Z. and Hölttä-Otto, K. (Eds.), Advances in Product Family and Product Platform Design, Springer, New York. https://doi.org/10.1007/9781-4614-7937-6 1

Sandau, R., Röser, H.P. and Valenzuela, A. (2008), Small Satellites for Earth Observation, Springer, Dordrecht. https://doi.org/1007/978-1-4020-6943-7

Sharma, K.J. and Bowonder, B. (2004), "The making of Boeing 777: a case study in concurrent engineering", International Journal of Manufacturing Technology and Management, Vol. 6 No. 3/4, pp. $254-264$. https://doi.org/10.1504/IJMTM.2004.005389

Shao, A., Wertz, J.R. and Koltz, E.A. (2017), "Quantifying the Cost Reduction Potential for Earth Observation Satellites", In: Hatton, S. (Ed.), Proceedings of the 12th Reinventing Space Conference, pp. 199-210. https://doi.org/10.1007/978-3-319-34024-1

Space X (2017), Space X home page. [online] Available at: http://www.spacex.com/ (accessed 29.12.2017).

Vaughn, A., Fernandes, P. and Shields, J.T. (2002), Manufacturing System Design Framework Manual, Massachusetts Institute of Technology. http://hdl.handle.net/1721.1/81902

Wheelwright, S.C. and Clark, K.B. (1992), Revolutionizing Product Development: Quantum Leaps in Speed, Efficiency, and Quality, Free Press, New York.

Prof. Anna B. Öhrwall Rönnback

Luleå University of Technology, Department of Business Administration, Technology and Social Sciences

Luleå University of Technology, 97187 Luleå, Sweden

Email: anna.ohrwall.ronnback@1tu.se 